\title{
Stack emission monitoring using non-dispersive infrared spectroscopy with an optimized nonlinear absorption cross interference correction algorithm
}

\author{
Y. W. Sun ${ }^{1, *}$, C. Liu ${ }^{2, *}$, K. L. Chan ${ }^{3}$, P. H. Xie ${ }^{1}$, W. Q. Liu ${ }^{1}$, Y. Zeng ${ }^{1}$, S. M. Wang ${ }^{1}$, S. H. Huang ${ }^{1}$, J. Chen ${ }^{1}$, \\ Y. P. Wang ${ }^{1}$, and F. Q. Si ${ }^{1}$ \\ ${ }^{1}$ Key Laboratory of Environmental Optics and Technology, Anhui Institute of Optics and Fine Mechanics, \\ Chinese Academy of Sciences, Hefei 230031, China \\ ${ }^{2}$ Harvard-Smithsonian Center for Astrophysics, Harvard University, Cambridge, MA, USA \\ ${ }^{3}$ School of Energy and Environment, City University of Hong Kong, Hong Kong \\ * These two authors contributed equally to this work.
}

Correspondence to: C. Liu (chliu@cfa.harvard.edu) and Y. W. Sun (ywsun@aiofm.ac.cn)

Received: 27 November 2012 - Published in Atmos. Meas. Tech. Discuss.: 21 February 2013

Revised: 8 June 2013 - Accepted: 2 July 2013 - Published: 13 August 2013

\begin{abstract}
.
In this paper, we present an optimized analysis algorithm for non-dispersive infrared (NDIR) to in situ monitor stack emissions. The proposed algorithm simultaneously compensates for nonlinear absorption and cross interference among different gases. We present a mathematical derivation for the measurement error caused by variations in interference coefficients when nonlinear absorption occurs. The proposed algorithm is derived from a classical one and uses interference functions to quantify cross interference. The interference functions vary proportionally with the nonlinear absorption. Thus, interference coefficients among different gases can be modeled by the interference functions whether gases are characterized by linear or nonlinear absorption. In this study, the simultaneous analysis of two components $\left(\mathrm{CO}_{2}\right.$ and $\mathrm{CO}$ ) serves as an example for the validation of the proposed algorithm. The interference functions in this case can be obtained by least-squares fitting with third-order polynomials. Experiments show that the results of cross interference correction are improved significantly by utilizing the fitted interference functions when nonlinear absorptions occur. The dynamic measurement ranges of $\mathrm{CO}_{2}$ and $\mathrm{CO}$ are improved by about a factor of 1.8 and 3.5, respectively. A commercial analyzer with high accuracy was used to validate the $\mathrm{CO}$ and $\mathrm{CO}_{2}$ measurements derived from the NDIR analyzer
\end{abstract}

prototype in which the new algorithm was embedded. The comparison of the two analyzers show that the prototype works well both within the linear and nonlinear ranges.

\section{Introduction}

In the infrared wavelength band between 2 and $10 \mu \mathrm{m}$, many gases exhibit strong absorption and interference with each other (Liu et al., 2011; Gary, 2002; Hikmat et al., 2009; Mauri et al., 2001). The accuracy and sensitivity of non-dispersive infrared (NDIR) measurement techniques are strongly influenced by cross influences among different gases. Thus, cross interference correction is necessary (Sayed and Mohamed, 2010; Bingham and Burton, 1984; Tyson et al., 1984; Lopez and Frutos, 1993). Most NDIR multi-gas analyzers use a look-up table, a matrix consisting of channel-to-channel interference constants, to correct cross interference (Herget et al., 1976; Jong et al., 2010; Dirk et al., 2009; Harold et al., 1999). However, the way of acquiring interference constants is different. Dirk et al. (2009) assumed that the total absorption signal measured at one filter channel is the sum of the absorption of each individual gas. Thus, the interference constants of different filter channels can be measured by filling the sample cell with different 
nominal gases (Dirk et al., 2009). On the contrary, Harold et al. (1999) previously calculated the absorption coefficients of a gas both at the intended and the interference filter channels by the line-by-line (LBL) calculation algorithm (Harold et al., 1999), and then the interference constant can be obtained by the ratio of the absorption coefficient at the interference channel and the one at the intended channel (Harold et al., 1999; Martin and Michael, 1999; Sparks, 1997).

Within a certain concentration range, an NDIR analyzer has a good linearity, and the Lambert-Beer law can be simplified as a linear equation. The cross interference can be corrected effectively by just using the interference constants (Dirk et al., 2009; Heusinkveld et al., 2008). In this case, each gas can be measured with high accuracy. However, a specified NDIR analyzer, which has a constant optical path length, exhibits nonlinear absorption (i.e., measurement is no longer linear to the absorption) if gas concentrations are too high (Andre et al., 1985). In this case, the channel-to-channel interference coefficient is no longer a constant. If cross interference is corrected by using a constant factor, correction error increases and measurement accuracy declines. Furthermore, such kind of measurement errors cannot be corrected through zero or span calibrations (Mark et al., 1983). In fact, no matter which technique of interference constant acquisition is used, using only a constant factor to quantify gas-togas interference is less than optimal, feasible only if the analyzer has excellent linearity for all gases. However, the linear region restricts the dynamic range of a system. By using two or more filter channels to analyze one gas, the conflict between linearity and dynamic range can be solved to some extent. However, this approach significantly increases the cost of analyzer production and difficulty for data processing.

In this paper, the cross interference coefficients are replaced by polynomial functions when nonlinear absorption exists. Thus, the dynamic measurement range of an NDIR analyzer can be expanded by correcting the cross interference and nonlinear absorption. In this study, we present a detailed description of the optimized algorithm. Laboratory and field experiments were preformed to test the algorithm.

\section{Classical algorithm and error analysis}

For an NDIR analyzer, within a restricted concentration range, measurement is nearly linear to the absorption. Cross interference can be corrected by setting up a series of simultaneous equations as follows (Bingham and Burton, 1984; Dirk et al., 2009; Harold et al., 1999).

$$
\left\{\begin{array}{c}
A_{\text {total }}^{1}=\ln \left(\frac{I_{0}^{1} / I_{0}^{\text {ref }}}{I_{s}^{1} / I_{s}^{\text {ref }}}\right)=k_{11} A_{1}+k_{12} A_{2}+k_{13} A_{3}+\ldots+k_{1 n} A_{n}, \\
A_{\text {total }}^{2}=\ln \left(\frac{I_{0}^{2} / I_{0}^{\text {ref }}}{I_{s}^{2} / I_{s}^{\text {ref }}}\right)=k_{21} A_{1}+k_{22} A_{2}+k_{23} A_{3}+\ldots+k_{2 n} A_{n}, \\
\ldots, \\
A_{\text {total }}^{n}=\ln \left(\frac{I_{0}^{n} / I_{0}^{\text {ref }}}{I_{s}^{n} / I_{s}^{\text {ref }}}\right)=k_{n 1} A_{1}+k_{n 2} A_{2}+k_{n 3} A_{3}+\ldots+k_{n n} A_{n},
\end{array}\right.
$$

where $A_{\text {total }}^{i}$ represents the total absorbance of channel \#i, $I_{0}^{i}$ and $I_{s}^{i}$ represent incident and emergent intensity, respectively, at channel $\# i, I_{0}^{\mathrm{ref}}$ and $I_{s}^{\text {ref }}$ represent incident and emergent intensity, respectively, at the reference filter channel, and all of which are measured by a detector. The reference channel is used to adjust any additional cause of attenuation: scattering by dust, the effect of impurities deposited on instrument windows, or any uncontrolled variation of source spectral luminance because of ageing or voltage fluctuations. The interference coefficient of gas $j$ to gas $i$ (or in other words, the interference coefficient of channel $\# j$ to channel $\# i)$ is denoted as $k_{i j} . A_{i}$ represents the pure absorbance of gas $i$. By solving Eq. (1), the pure absorbance of each gas can be obtained. The pure absorbance can then be used for concentration retrieval with calibration curves. Here, $i, j=1 \sim n$ and $k_{i=j}=1$; that is, a gas has zero interference to itself.

By way of a non-limiting example, assume that two gases are used for measurement and that they interfere with each other. The two gases are denoted as $i$ and $j$. Assume that filter channels $\# i$ and $\# j$, with bandwidths of $i$ and $j$, respectively, are designed to measure gas $i$ and gas $j$, respectively. The absorption coefficients of gas $i$ within $i$ and $j$ are $\alpha_{i}$ and $\beta_{i}$, respectively, and those of gas $j$ within $i$ and $j$ are $\alpha_{j}$ and $\beta_{j}$, respectively. $\alpha_{i}, \beta_{i}, \alpha_{j}$, and $\beta_{j}$ are calculated by LBL integration of the line strengths provided by the HITRAN database over the relevant wavelength range (see Sect. 1) (Sparks, 1997; Rothman et al., 2005, 2009). If the absorption is linear to the concentration, the calibration curves of gas $i$ and $j$ and the interference coefficient of gas $i$ to $j k_{j i}$ and gas $j$ to $i k_{i j}$ can be written as

$$
\begin{aligned}
& C_{i}=\frac{1}{\alpha_{i} L} \times A_{i} ; \quad C_{j}=\frac{1}{\beta_{j} L} \times A_{j} ; \\
& k_{j i}=\frac{\beta_{i}}{\alpha_{i}} ; \quad k_{i j}=\frac{\alpha_{j}}{\beta_{j}} .
\end{aligned}
$$

Here, $C_{i}$ and $C_{j}$ represent the concentrations of gas $i$ and $j$, respectively. $L$ is the optical-path length. $\alpha_{i}, \beta_{i}, \alpha_{j}, \beta_{j}, k_{j i}$, $k_{i j}$, and $L$ are known constants for a specified NDIR multigas analyzer. Thus, regardless of the proportions of the gas mixture of gas $i$ and $j$, the total absorbance of channels \#i and $\# j$ can always be expressed as a linear superposition of the pure absorbance of gas $i$ and $j$, respectively.

$$
\left\{\begin{array}{l}
A_{\text {total }}^{i}=\ln \left(\frac{I_{0}^{i} / I_{0}^{\text {ref }}}{I_{s}^{i} / I_{s}^{\text {ref }}}\right)=A_{i}+\frac{\alpha_{j}}{\beta_{j}} A_{j} \\
A_{\text {total }}^{j}=\ln \left(\frac{I_{0}^{j} / I_{0}^{\text {ref }}}{I_{s}^{j} / I_{s}^{\text {ref }}}\right)=\frac{\beta_{i}}{\alpha_{i}} A_{i}+A_{j}
\end{array}\right.
$$

By solving Eq. (3), the absorbance of $A_{i}$ and $A_{j}$ can be obtained. The concentrations of gas $i$ and $j$ can be retrieved by the calibration curves in Eq. (2) with high accuracy. Thus, in theory, the cross interference is completely corrected. However, if gas $i$ and/or $j$ concentration lies beyond a restricted range, nonlinear absorption occurs, and measurement accuracy declines because correction error increases. We assume 
that the calibration curves of gas $i$ and $j$ are transformed from linear curves to nonlinear functions, represented as $C_{i}=F\left(A_{i}\right)$ and $C_{j}=G\left(A_{j}\right)$, respectively. The interference coefficients $k_{j i}$ and $k_{i j}$ are transformed into $k_{j i}^{\prime}$ and $k_{i j}^{\prime}$, respectively. In this case, the total absorbance of channels \#i and $\# j$ is expressed as

$$
\left\{\begin{array}{c}
A_{\text {total }}^{i}=\ln \left(\frac{I_{0}^{i} / I_{0}^{\text {ref }}}{I_{s}^{i} / I_{s}^{\text {ref }}}\right)=F^{-1}\left(C_{i}\right)+k_{i j}^{\prime} G^{-1}\left(C_{j}\right) \\
A_{\text {total }}^{j}=\ln \left(\frac{I_{0}^{j} / I_{0}^{\text {ref }}}{I_{s}^{j} / I_{s}^{\text {ref }}}\right)=k_{j i}^{\prime} F^{-1}\left(C_{i}\right)+G^{-1}\left(C_{j}\right) .
\end{array}\right.
$$

Here, $F^{-1}\left(C_{i}\right)$ and $G^{-1}\left(C_{j}\right)$ are the inverse functions of $F\left(A_{i}\right)$ and $G\left(A_{j}\right)$, respectively. By solving Eqs. (3) and (4), $A_{i}, A_{j}, F^{-1}\left(C_{i}\right)$, and $G^{-1}\left(C_{j}\right)$ are expressed as

$$
\begin{gathered}
A_{i}=\frac{\alpha_{i} \alpha_{j} \ln \left(\frac{I_{0}^{j} / I_{0}^{\mathrm{ref}}}{I_{s}^{j} / I_{s}^{\mathrm{ref}}}\right)-\beta_{j} \alpha_{i} \ln \left(\frac{I_{0}^{i} / I_{s}^{\mathrm{ref}}}{I_{s}^{i} / I_{s}^{\text {ref }}}\right)}{\alpha_{j} \beta_{i}-\alpha_{i} \beta_{j}}, \\
A_{j}=\frac{\beta_{i} \beta_{j} \ln \left(\frac{I_{0}^{i} / I_{0}^{\mathrm{ref}}}{I_{s}^{i} / I_{s}^{\mathrm{ref}}}\right)-\beta_{j} \alpha_{i} \ln \left(\frac{I_{0}^{j} / I_{0}^{\mathrm{ref}}}{I_{s}^{j} / I_{s}^{\mathrm{ref}}}\right)}{\alpha_{j} \beta_{i}-\alpha_{i} \beta_{j}}, \\
F^{-1}\left(C_{i}\right)=\frac{\ln \left(\frac{I_{0}^{i} / I_{0}^{\mathrm{ref}}}{I_{s}^{i} / I_{s}^{\text {ref }}}\right)-k_{i j}^{\prime} \ln \left(\frac{I_{0}^{j} / I_{0}^{\mathrm{ref}}}{I_{s}^{j} / I_{s}^{\mathrm{ref}}}\right)}{1-k_{i j}^{\prime} k_{j i}^{\prime}},
\end{gathered}
$$

and

$$
G^{-1}\left(C_{j}\right)=\frac{\ln \left(\frac{I_{0}^{j} / I_{s}^{\mathrm{ref}}}{I_{s}^{j} / I_{s}^{\mathrm{ref}}}\right)-k_{j i}^{\prime} \ln \left(\frac{I_{0}^{i} / I_{s}^{\mathrm{ref}}}{I_{s}^{i} / I_{s}^{\text {ref }}}\right)}{1-k_{i j}^{\prime} k_{j i}^{\prime}} .
$$

If the interference equations are set up by using the previous interference constants, then

$$
\left\{\begin{array}{c}
F^{-1}\left(C_{i}\right)+k_{i j}^{\prime} G^{-1}\left(C_{j}\right)=A_{i}+\frac{\alpha_{j}}{\beta_{j}} A_{j} \\
k_{j i}^{\prime} F^{-1}\left(C_{i}\right)+G^{-1}\left(C_{j}\right)=\frac{\beta_{i}}{\alpha_{i}} A_{i}+A_{j} .
\end{array}\right.
$$

The relative measurement error is defined as

$\gamma=\frac{C_{\text {measured }}-C_{\text {true }}}{C_{\text {true }}} \times 100 \%$,

where $C_{\text {measured }}$ is the concentration retrieved by using the interference constants, and $C_{\text {true }}$ is the concentration retrieved by using the actual interference coefficients. Consequently, the measurement error of gas $i \gamma_{i}$ and $j \gamma_{j}$ can be mathematically calculated as

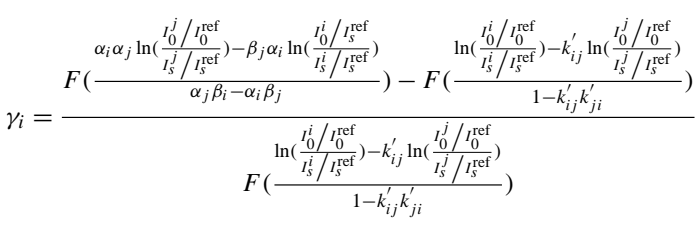

and

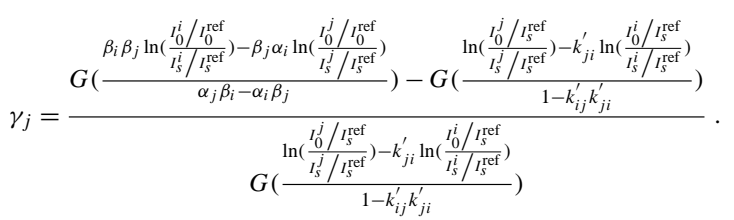

All parameters in Eqs. (9) and (10) are known, and the nonlinear functions $F(x)$ and $G(x)$ can be obtained by leastsquares fitting using low-order polynomials (Yan et al., 2009; Komhyr et al., 1983, 1989; Bjorck, 1996; Rao et al., 1999; Derek, 1968; Marcel et al., 1990). Therefore, gases $i$ and $j$ have measurement errors of $\gamma_{i}$ and $\gamma_{j}$ because of the variations of calibration curves and interference coefficients. These variations are caused by nonlinear absorption. Both $\gamma_{i}$ and $\gamma_{j}$ are related to $k_{j i}^{\prime}$ and $k_{i j}^{\prime}$. To find whether $k_{j i}^{\prime}$ and $k_{i j}^{\prime}$ are influenced by the concentrations of gas $i$ and $j$, experiments are conducted several times. The results are listed in Table 1 , in which four different cases can be identified. $\gamma_{i}$ and $\gamma_{j}$ are zero only if the absorption is linear for both gases (i.e., case 1). However, neither $\gamma_{i}$ nor $\gamma_{j}$ equals zero for all other cases (i.e., cases 2, 3, and 4). These results mean that the classical algorithm can correct cross interference completely if an analyzer does not exhibit nonlinear absorption. However, once gas $i$ and/or $j$ have/has nonlinear absorption, the classical algorithm fails, producing a measurement error because of its imperfection.

\section{An optimized algorithm}

A modification of interference Eq. (1) can effectively correct the measurement error produced by the imperfection of the classical algorithm when the analyzer exhibits nonlinear absorption. Taking the above-mentioned gases $i$ and $j$ as an example, an interference function rather than an interference constant is used to qualify the gas-to-gas interference, in total contrast to the classical algorithm, even though the optimized algorithm also requires zero and span calibrations.

Assume that the interference functions of gas $i$ to $j$ and $j$ to $i$ are represented as $k_{j i}(x)$ and $k_{i j}(x)$, respectively. A modification of interference Eq. (1) can be written as

$\left\{\begin{array}{c}A_{\text {total }}^{i}=\ln \left(\frac{I_{0}^{i} / I_{0}^{\text {ref }}}{I_{s}^{i} / I_{s}^{\text {ref }}}\right)=A_{i}+k_{i j}\left(A_{j}\right) \\ A_{\text {total }}^{j}=\ln \left(\frac{I_{0}^{j} / I_{0}^{\text {ref }}}{I_{s}^{j} / I_{s}^{\text {ref }}}\right)=k_{j i}\left(A_{i}\right)+A_{j} .\end{array}\right.$

The optimized interference Eq. (11) applies not only to linear absorption but also to nonlinear absorption, resulting in great improvements in the dynamic measurement range of an NDIR analyzer, because $k_{j i}(x)$ and $k_{i j}(x)$ vary with the concentrations of gas $i$ and $j$, respectively. In fact, classical interference equations can also be derived from optimized ones; that is, they can be derived from each other (see Sect. 4.3 for details). Both $k_{j i}(x)$ and $k_{i j}(x)$ can be obtained by leastsquares fitting (Yan et al., 2009; Komhyr et al., 1983, 1989; 
Table 1. Interference coefficient behavior.

\begin{tabular}{|c|c|c|c|c|}
\hline Case & $\begin{array}{l}\text { Nonlinear absorption } \\
\text { behavior }\end{array}$ & $k_{j i}^{\prime}$ & $k_{i j}^{\prime}$ & $\begin{array}{l}\text { Measurement } \\
\text { error }\end{array}$ \\
\hline 1 & $\begin{array}{l}\text { Neither gas } i \text { nor } j \\
\text { has nonlinear absorption. }\end{array}$ & $k_{j i}^{\prime}=k_{j i}$ & $k_{i j}^{\prime}=k_{i j}$ & $\begin{array}{l}\gamma_{i}=0 \\
\gamma_{j}=0\end{array}$ \\
\hline 2 & $\begin{array}{l}\text { Gas } i \text { has nonlinear } \\
\text { absorption, but gas } j \\
\text { does not. }\end{array}$ & $\begin{array}{l}k_{j i}^{\prime}>k_{j i} \text { and varies } \\
\text { obviously with gas } i \\
\text { concentration, increasing } \\
\text { as its concentration } \\
\text { increases. }\end{array}$ & $k_{i j}^{\prime}=k_{i j}$ & $\begin{array}{l}\gamma_{i} \neq 0 \\
\gamma_{j} \neq 0\end{array}$ \\
\hline 3 & $\begin{array}{l}\text { Gas } j \text { has nonlinear } \\
\text { absorption, but gas } i \\
\text { does not. }\end{array}$ & $k_{j i}^{\prime}=k_{j i}$ & $\begin{array}{l}k_{i j}^{\prime}>k_{i j} \text { and varies } \\
\text { obviously with gas } j \\
\text { concentration, increasing } \\
\text { as its concentration } \\
\text { increases. }\end{array}$ & $\begin{array}{l}\gamma_{i} \neq 0 \\
\gamma_{j} \neq 0\end{array}$ \\
\hline 4 & $\begin{array}{l}\text { Both gas } i \text { and } j \\
\text { have nonlinear } \\
\text { absorption. }\end{array}$ & $\begin{array}{l}k_{j i}^{\prime}>k_{j i} \text { and } k_{i j}^{\prime}>k_{i j} . \mathrm{B} \\
\text { and } j \text { concentration, respe }\end{array}$ & $\begin{array}{l}\text { th of them vary obviously with gas } i \\
\text { tively, increasing as their concentrations increase. }\end{array}$ & $\begin{array}{l}\gamma_{i} \neq 0 \\
\gamma_{j} \neq 0\end{array}$ \\
\hline
\end{tabular}

Bjorck, 1996; Rao et al., 1999; Derek, 1968; Marcel et al., 1990), which is similar to the acquisition method for calibration curves. Details of the procedure are as follows.

\subsection{Interference function of gas $i$ to $j k_{j i}(x)$}

Gas $i$ with various concentrations, from low to high, is pumped into a sample cell. The concentration should preferably be prepared as more than 10 different levels and evenly distributed within the entire range. The voltages measured at the $\# i$ and $\# j$ channels are in ratio against the voltages measured at the reference channel to correct for hardware instability, and are then converted to absorbance. Least-squares fitting with an ideal model is adopted to treat the data array $\left(A_{\text {total }_{(h)}}^{i}, A_{\text {total }_{(h)}}^{j}\right)$. Thus, the interference function of gas $i$ to $j$ is obtained. Here, $A_{\text {total }_{(h)}}^{i}$ and $A_{\text {total }_{(h)}}^{j}$ are the total absorbance of channels \#i and \# $j$ when gas $i$ is pumped into the sample cell for the $h$ th time $(h=1 \sim n)$.

\subsection{Interference function of gas $j$ to $i k_{i j}(x)$}

Similar to $k_{j i}(\mathrm{x}), k_{i j}(\mathrm{x})$ is obtained by pumping gas $j$ into the sample cell. The result data array is $\left(A_{\operatorname{total}_{(h)}^{j}}^{j}, A_{\operatorname{total}_{(h)}}^{i}\right)$.

In fact, the interference function is related to the characteristics of the filters designed for gas analysis, such as bandwidth, center wavelength, and transmission. For a specified NDIR multi-gas analyzer, the gas-to-gas interference can be estimated by using the literature absorption parameters. In this study, literature absorption parameters from the HITRAN database were used (Rothman et al., 2005, 2009). If the interference constant obtained by LBL calculation is negligible (Harold et al., 1999; Martin and Michael, 1999; Sparks, 1997), the interference function can be set to zero.
If the absorption is pronounced, a reasonable model should be selected for least-squares fitting. In principle, any kind of model, such as a polynomial, exponential, or logarithm function, is feasible as long as the fitting correlation coefficient $r$ is sufficiently close to 1 . However, a model must not be too complex, because the more complex the interference function is, the more complicated the interference equations are to be solved. The most interesting thing is that any derivative function can be Taylor-expanded into a power series. Thus, power series is an ideal model, which not only effectively models the nonlinear variation of interference coefficient but also facilitates the solving of the interference equations (Andre et al., 1985). In our case, a model of third-order polynomials is selected.

\section{Experimental sections}

\subsection{Apparatuses}

Figure 1 shows the structure of the NDIR multi-gas analyzer prototype used for experiments. The instrument includes an infrared (IR) light source, an optical filter wheel, a sample cell, a detector, and a data processor. The filter wheel has eight filters for the optical signal at certain wavelength bands. By using different filter combinations, the instrument can be used to measure different gases, such as $\mathrm{SO}_{2}, \mathrm{NO}_{2}, \mathrm{CH}_{4}$, $\mathrm{N}_{2} \mathrm{O}, \mathrm{HC}, \mathrm{H}_{2} \mathrm{O}, \mathrm{CO}_{2}, \mathrm{CO}, \mathrm{NO}, \mathrm{NO}_{2}$, and $\mathrm{H}_{2} \mathrm{~S}$. Detailed descriptions of this prototype can be found in Sun et al. (2011). For clarity, we take simultaneous $\mathrm{CO}_{2}$ and $\mathrm{CO}$ analyses as an example in the following discussion. $\mathrm{CO}_{2}$ and $\mathrm{CO}$ correspond to gases $i$ and $j$ mentioned in Sect. 2, respectively. Expansion to more than two gases is straightforward. 


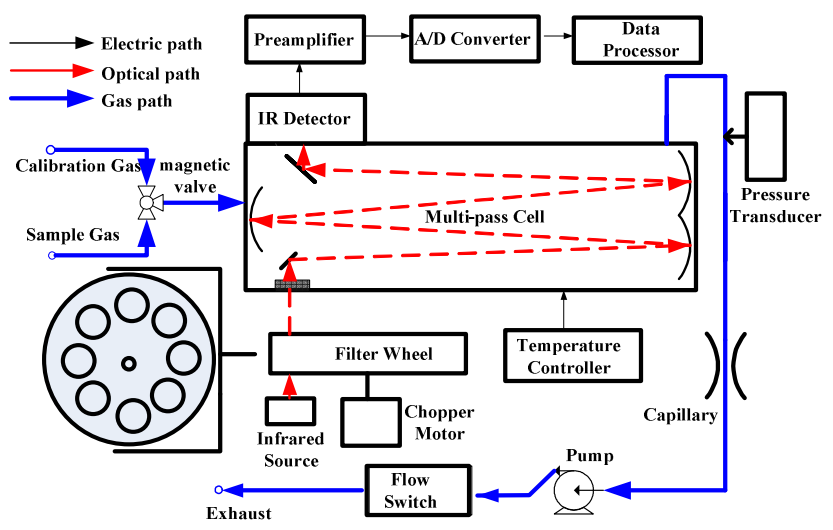

Fig. 1. Functional structure of the NDIR multi-gas analyzer prototype used for experiments.

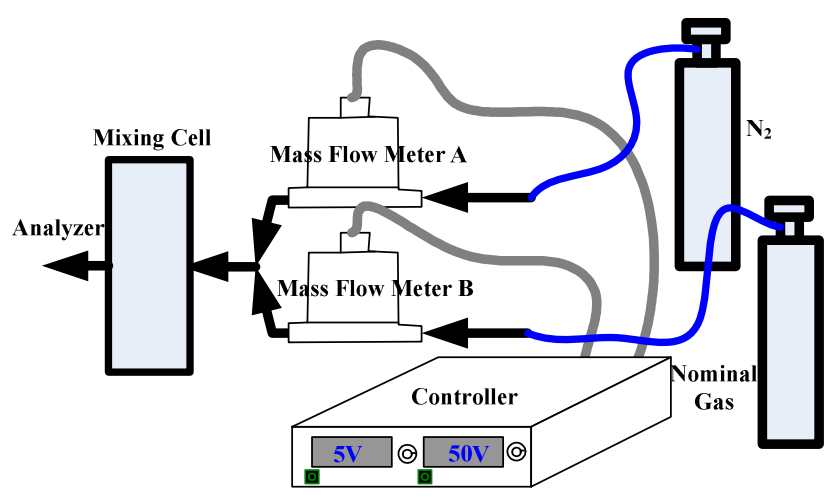

Fig. 2. Functional structure of the gas distribution system used for laboratory experiments.

A gas distribution system used for laboratory experiments is shown in Fig. 2. Gas concentrations from $10 \%$ to $90 \%$ of nominal value can be obtained with a precision of $\pm 0.5 \%$ by varying the voltages of the two mass flow meters. For the analysis presented here, measurement error caused by the gas distribution system was neglected.

\subsection{Laboratory experiments and discussions}

Figures 3 and 4 show calibration curves and measurement linearity fitting results for $\mathrm{CO}_{2}$ and $\mathrm{CO}$, respectively. A thirdorder polynomial was used to fit the relation between gas concentration and absorbance. The parameters of the fitted polynomial and corresponding estimated errors are shown in the figures. The correlation coefficients of polynomial fittings for $\mathrm{CO}_{2}$ and $\mathrm{CO}$ measurements are 0.99991 and 0.99998 , respectively. The polynomials of the calibration curves of $\mathrm{CO}_{2}$ and $\mathrm{CO}$ are expressed as Eqs. (12) and (13), respectively.

$$
\begin{aligned}
C\left(\mathrm{CO}_{2}\right) & =(0.040622 \pm 0.007012) \\
& +(111.70135 \pm 6.04867) \times\left(A_{i}\right) \\
& +(477.13268 \pm 123.79041) \times\left(A_{i}\right)^{2} \\
& +(215.01234 \pm 63.20941) \times\left(A_{i}\right)^{3}
\end{aligned}
$$

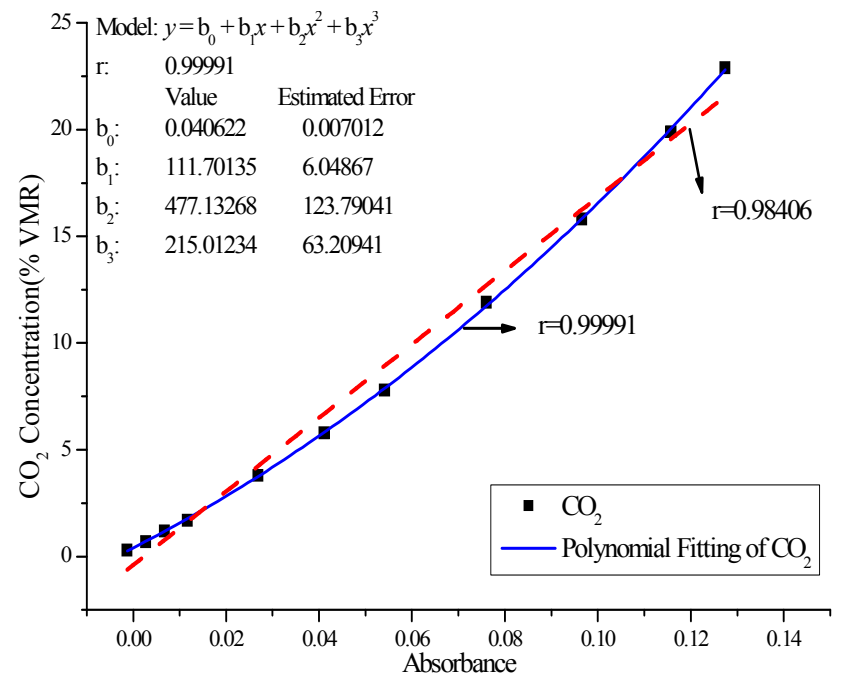

Fig. 3. Calibration curve and measurement linearity fitting results for $\mathrm{CO}_{2}$. The red dotted line is the linear plot fitted by linear leastsquares fitting, and the blue solid curve represents the calibration curve obtained by least-squares fitting using the third-order polynomial model. Fitting values, estimated errors, and fitting correlation coefficients are also included.

$$
\begin{aligned}
C(\mathrm{CO}) & =(2.29864 \pm 0.446215) \\
& +(268.19825 \pm 15.03105) \times\left(A_{j}\right) \\
& +(11936.11652 \pm 848.8231) \times\left(A_{j}\right)^{2} \\
& +(-8850.98731 \pm 1364.9827) \times\left(A_{j}\right)^{3}
\end{aligned}
$$

According to Figs. 3 and 4, nonlinear absorptions exist for $\mathrm{CO}_{2}$ and $\mathrm{CO}$ (fitting correlation coefficients for third-order polynomial models are significantly higher than those of the linear models). For effective modeling of nonlinear absorption when NDIR technique is used for simultaneous multigas analysis, a typical power series model is used. Generally, the higher the order, the more complex the calibration curve and the higher the modeling precision (i.e., the more $r$ is sufficiently close to 1). Tan et al. (2008) used two third-order polynomials to calibrate both $\mathrm{CO}_{2}$ and $\mathrm{CH}_{4}$ channels in their mini NDIR analyzer (Tan et al., 2008). However, the NDIR analyzer L-7500 manufactured by Li-Cor uses a five-order polynomial to calibrate $\mathrm{CO}_{2}$ but a third-order polynomial to calibrate $\mathrm{H}_{2} \mathrm{O}$ (Instruction Manual-L-7200/7500). In this study, both $\mathrm{CO}_{2}$ and $\mathrm{CO}$ are calibrated by using a third-order polynomial, a reasonable choice because of sufficiently high fitting correlation coefficients.

Figures 5 and 6 show the fitted interference functions (details about fitting procedures are shown in Sect. 3). Fitting values, estimated errors, and fitting correlation coefficients are clearly visible in both figures. More precisely, Figure 5 shows the fitting results for the interference function of $\mathrm{CO}_{2}$ to $\mathrm{CO}$, and Fig. 6 shows those of $\mathrm{CO}$ to $\mathrm{CO}_{2}$. The fitted interference functions of $\mathrm{CO}_{2}$ to $\mathrm{CO}$ and $\mathrm{CO}$ to $\mathrm{CO}_{2}$ are expressed 


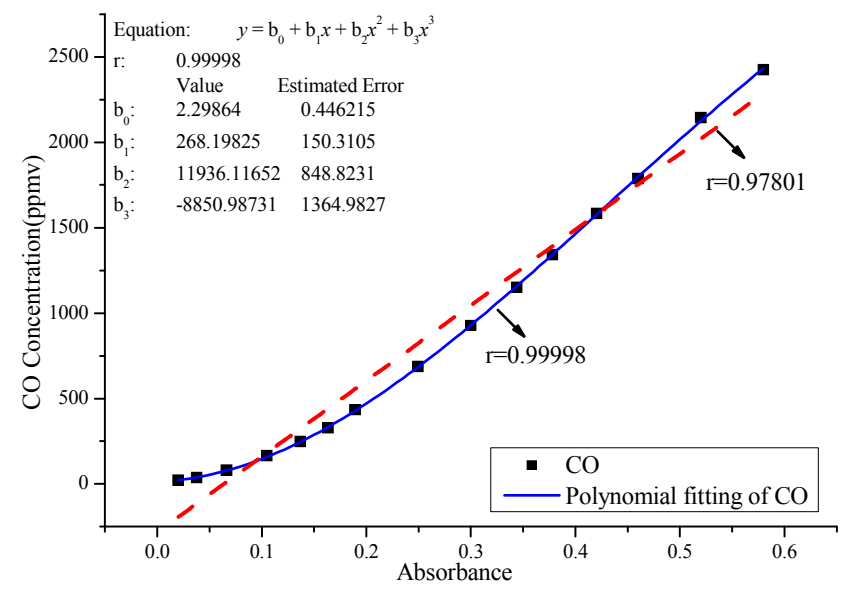

Fig. 4. Calibration curve and measurement linearity fitting results for CO. The red dotted line is the linear plot fitted by linear leastsquares fitting, and the blue solid curve represents the calibration curve obtained by least-squares fitting using the third-order polynomial model. Fitting values, estimated errors, and fitting correlation coefficients are also included.

as Eqs. (14) and (15), respectively.

$$
\begin{aligned}
& k_{j i}\left(A_{i}\right)=\left(7.89297 \times 10^{-4} \pm 2.80151 \times 10^{-5}\right) \\
& +(0.23715 \pm 0.00168) \times\left(A_{i}\right)+(-0.02213 \\
& \pm 0.002665) \times\left(A_{i}\right)^{2}+(1.63133 \pm 0.12229) \times\left(A_{i}\right)^{3}
\end{aligned}
$$

$$
\begin{aligned}
& k_{i j}\left(A_{j}\right)=\left(-0.00491 \pm 3.86852 \times 10^{-4}\right) \\
& +(0.53734 \pm 0.00818) \times\left(A_{j}\right)+(-0.02726 \\
& \pm 0.004046) \times\left(A_{j}\right)^{2}+(0.91542 \pm 0.04961) \times\left(A_{j}\right)^{3}
\end{aligned}
$$

Figures 5 and 6 show a linear relation between the absorbance of $\mathrm{CO}$ and $\mathrm{CO}_{2}$ for concentrations below a critical threshold, where the interference coefficients only have invisible variations. Thus, the interference coefficient within this measurement range can be accurately approximated as a constant. However, if the concentration exceeds this range, the actual interference coefficient is no longer linear. The difference between the actual interference coefficient and the linearly approximated interference coefficient increases with the concentration, which is in good agreement with Table 1. The actual interference coefficients in Figs. 5 and 6 are cal-

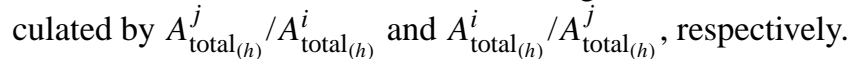
In fact, the deviation point is around $0.1\left(\sim 17 \% \mathrm{CO}_{2}\right.$ volume mixture ratio (VMR)) for Fig. 5 and around 0.3 $(\sim 850$ ppmv CO VMR) for Fig. 6 . Figure 5 shows that, if $\mathrm{CO}_{2}$ concentration is within $17 \%$, the interference of $\mathrm{CO}_{2}$ to $\mathrm{CO}$ can be effectively modeled by both the fitted interference function and $y=0.2535 x$. However, if $\mathrm{CO}_{2}$ concentration exceeds $17 \%$, a polynomial model works much better than a linear model and results in lower error. Similarly, as shown in Fig. 6, if CO concentration is within 850 ppmv, the interference of $\mathrm{CO}$ to $\mathrm{CO}_{2}$ can be effectively modeled by a linear or polynomial model. Once $\mathrm{CO}$ concentration

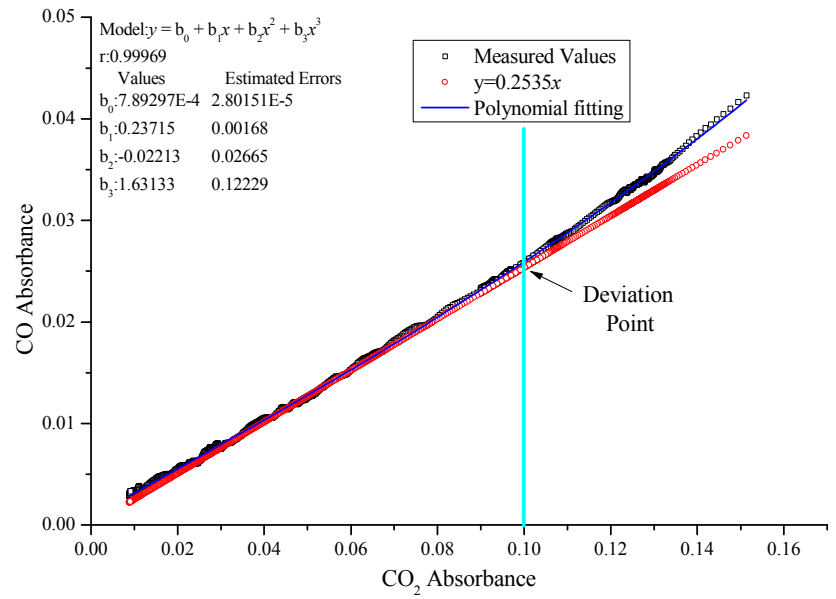

Fig. 5. Fitting results for the interference function of $\mathrm{CO}_{2}$ to $\mathrm{CO}$. The black squares are absorbance arrays converted from detection voltages, the solid blue line is the interference function obtained by least-squares fitting using a third-order polynomial, and the slope of the straight line marked by red circles is the interference constant of $\mathrm{CO}_{2}$ to $\mathrm{CO}$. Specifically, a data array marked by black squares corresponds to the array $\left(A_{\operatorname{total}_{(h)}}^{i}, A_{\text {total }_{(h)}}^{j}\right)$ mentioned in Sect. 3, the solid blue line is $k_{j i}(x)$, and the slope 0.2535 of $y=0.2535 \mathrm{x}$ is $k_{j i}$, which is measured through the method mentioned in Dirk et al. (2009).

exceeds $850 \mathrm{ppmv}$, only the fitted interference function can effectively model such interference, and $y=0.5525 x$ results in great error.

Similar to those of calibration curve fittings, the models used for interference function fittings are also third-order polynomials. Models are feasible because the fitting correlation coefficient $r$ is sufficiently close to 1 (0.99969 for Fig. 5 and 0.99986 for Fig. 6).

In this section, the measurement errors of different cross interference correction algorithms are compared. Figures 7 and 8 are comparisons of the interference corrections of $\mathrm{CO}_{2}$ to $\mathrm{CO}$ and $\mathrm{CO}$ to $\mathrm{CO}_{2}$, respectively. Figure $7 \mathrm{a}$ shows the $\mathrm{CO}$ concentrations calculated by using the $\mathrm{CO}$ calibration curve after correction for the interference by $\mathrm{CO}_{2}$. We take 100 ppmv $\mathrm{CO}$ as an example. The influence of different concentrations of $\mathrm{CO}_{2}$ on $\mathrm{CO}$ measurement errors calculated after interference correction is clearly visible in Fig. 7b. According to Fig. 7, $\mathrm{CO}_{2}$ interference can be effectively corrected by both algorithms if $\mathrm{CO}_{2}$ concentration is lower than $17 \%$. Measurement errors calculated after interference correction by both algorithms are less than $1 \%$. However, interference correction results with the fitted interference function are obviously better than those with the interference constant if $\mathrm{CO}_{2}$ concentration exceeds $17 \%$. In this case, the $\mathrm{CO}$ measurement errors for interference correction using the fitted interference function change by less than $1 \%$, whereas those for interference correction using a constant factor increase with increasing $\mathrm{CO}_{2}$ concentration. Similar to Fig. 7, Fig. 8 


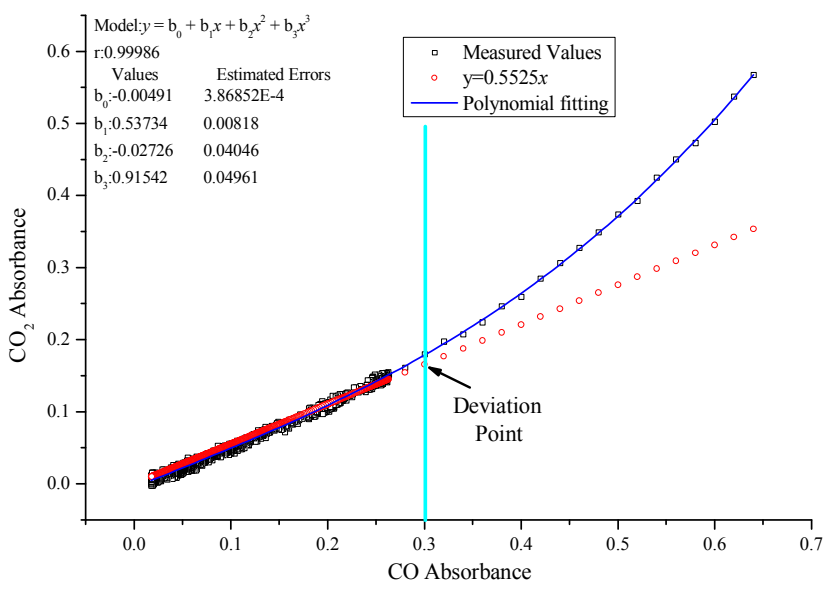

Fig. 6. Fitting results for the interference function of $\mathrm{CO}$ to $\mathrm{CO}_{2}$. The black squares are absorbance arrays converted from detection voltages, the solid blue line is the interference function obtained by least-squares fitting using a third-order polynomial, and the slope of the straight line marked by red circles is the interference constant of $\mathrm{CO}$ to $\mathrm{CO}_{2}$. Specifically, the data array marked by black squares corresponds to array $\left(A_{\operatorname{total}_{(h)}}^{j}, A_{\text {total }_{(h)}}^{i}\right)$, the solid blue line is $k_{i j}(x)$, and the slope 0.5525 of $y=0.5525 \mathrm{x}$ is $k_{i j}$, which is measured through the method mentioned in Dirk et al. (2009).

shows the $\mathrm{CO}_{2}$ concentration deviations between measurement results and the true values (in this case, different concentrations of $\mathrm{CO}$ are sequentially pumped into the sample cell for analysis, and the actual $\mathrm{CO}_{2}$ concentration should be zero because no $\mathrm{CO}_{2}$ is present). Figure $8 \mathrm{a}$ shows $\mathrm{CO}_{2}$ concentrations calculated by using the $\mathrm{CO}_{2}$ calibration curve after $\mathrm{CO}$ interference is corrected. Figure $8 \mathrm{~b}$ shows the influence of different concentrations of $\mathrm{CO}$ on $\mathrm{CO}_{2}$ measurement errors, for which $25 \% \mathrm{CO}_{2}$ is taken as an example. According to Fig. 8, $\mathrm{CO}$ interference can be corrected by both algorithms if $\mathrm{CO}$ concentration is within 850 ppmv. Measurement errors calculated after interference correction by both algorithms are less than $1.5 \%$. However, interference correction results with a polynomial interference function are obviously better than those with a constant factor when $\mathrm{CO}$ concentration exceeds $850 \mathrm{ppmv}$. The $\mathrm{CO}_{2}$ measurement errors for interference correction using the fitted interference function stay almost the same (still less than $1.5 \%$ ), whereas those for interference correction using a constant factor increase with $\mathrm{CO}$ concentration increases. In other words, the upper measurement range of this analyzer prototype for $\mathrm{CO}_{2}$ and CO is only $17 \%$ and 850 ppmv, respectively, if cross interference is corrected by a constant factor. However, if the optimized algorithm is used, upper measurement ranges are actually extended to $31 \%$ and 3000 ppmv for $\mathrm{CO}_{2}$ and $\mathrm{CO}$ measurements, respectively. Dynamic ranges for $\mathrm{CO}_{2}$ and $\mathrm{CO}$ are improved by a factor of 1.8 and 3.5, respectively.

According to Figs. 7 and 8, the influence of $\mathrm{CO}$ on $\mathrm{CO}_{2}$ measurement is larger than the influence of $\mathrm{CO}_{2}$ on $\mathrm{CO}$

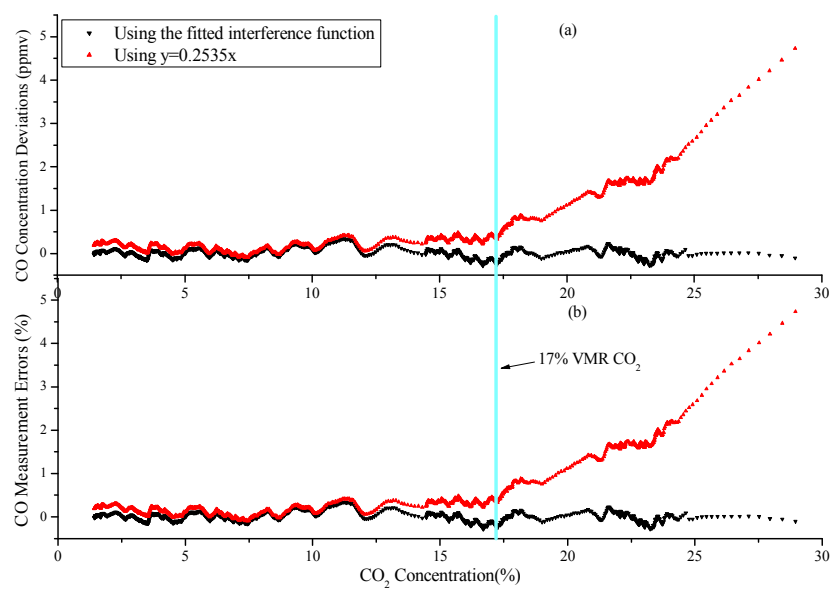

Fig. 7. Measurement error comparison for the different cross interference correction algorithms (with respect to the interference of $\mathrm{CO}_{2}$ to $\mathrm{CO}$ ). (a) Different concentrations of $\mathrm{CO}_{2}$ are pumped into a sample cell in sequence for analysis, but only the $\mathrm{CO}$ channel is used for concentration retrieval; the black inverted triangle curves and the red upright triangle curves are the $\mathrm{CO}$ concentration variations for the cross interference being corrected using the fitted interference function and a constant factor, respectively. (b) Measurement error variations calculated from (a) when 100 ppmv $\mathrm{CO}$ is taken as an example.

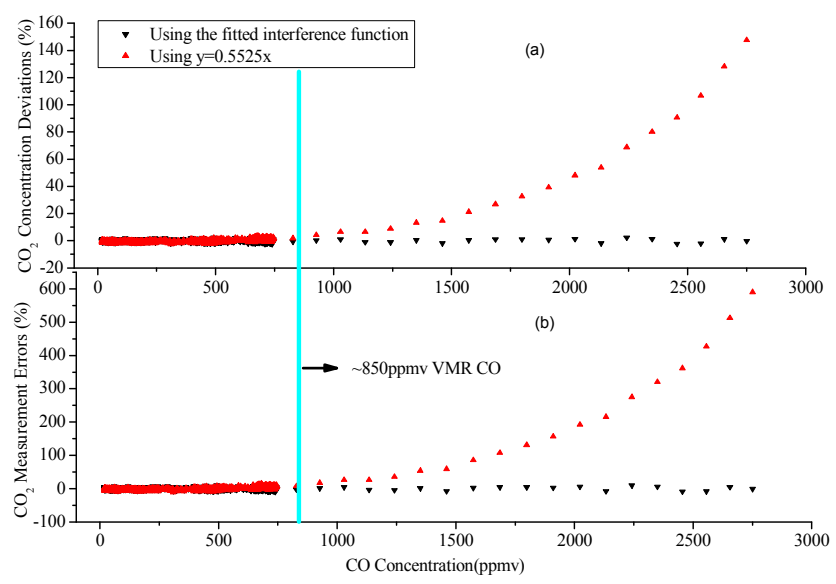

Fig. 8. Measurement error comparison for the different cross interference correction algorithms (with respect to the interference of $\mathrm{CO}$ to $\mathrm{CO}_{2}$ ). (a) Different concentrations of $\mathrm{CO}$ are pumped into a sample cell in sequence for analysis, but only the $\mathrm{CO}_{2}$ channel is used for concentration retrieval; the black inverted triangle curves and the red upright triangle curves are the $\mathrm{CO}_{2}$ concentration variations for the cross interference being corrected using the fitted interference function and a constant factor, respectively. (b) Measurement error variations calculated from (a) when $25 \% \mathrm{CO}_{2}$ is taken as an example.

measurement. Figure 8 shows that the measurement error of $\mathrm{CO}_{2}$ can exceed $100 \%$ if cross interference is corrected by using a constant factor when $\mathrm{CO}$ concentration exceeds 1000 ppmv. For example, $\mathrm{CO}_{2}$ measurement error is up to 


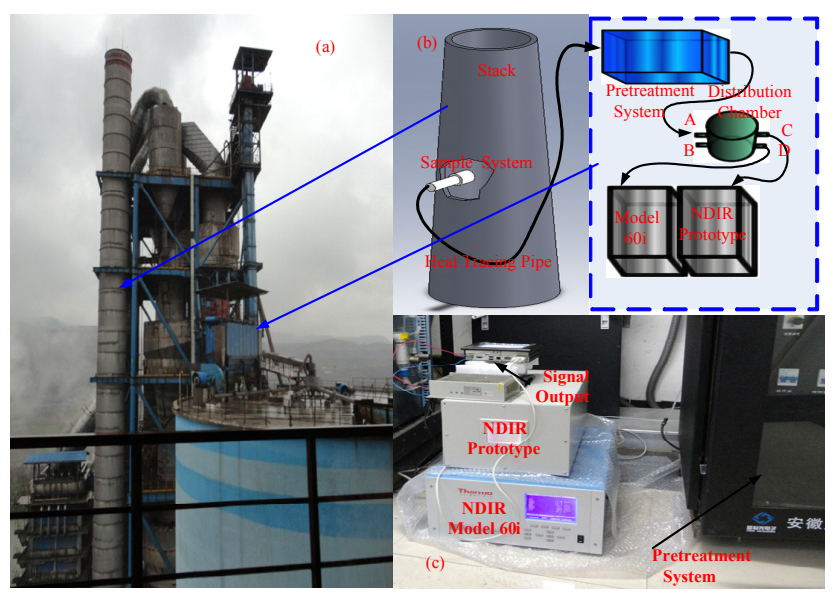

Fig. 9. Diagram of the experimental setup used in the field. Two analyzers are placed in a mini house built about $15 \mathrm{~m}$ above the ground. (a) A photo of the stack taken from a nearby building roof, (b) shows diagram of experimental setup used in the field and arrangement inside the mini house is visible in (c).

about $600 \%$ when $\mathrm{CO}$ concentration is $\sim 2700$ ppmv. In this case, the measurement results are totally unreliable, possibly because the NDIR multi-gas analyzer prototype is designed for continuous emissions monitoring systems installed at emission sources, such as power plants and incinerators. $\mathrm{CO}_{2}$ concentrations emitted by these facilities are extremely high. Thus, a relatively weaker absorption waveband centered at $4.84 \mu \mathrm{m}$ (rather than $4.30 \mu \mathrm{m}$ ) is selected. This wavelength band has a stronger response to $\mathrm{CO}$ than to $\mathrm{CO}_{2}$. Thus, the measurement accuracy of $\mathrm{CO}_{2}$ would be severely affected if $\mathrm{CO}$ interference was not completely corrected.

The exact similarity between the absorbance arrays used for the two different algorithms should be noted for comparison. Figures 7 and 8 show that measurement errors calculated after interference correction by two algorithms have approximately the same rapid variations. These variations are currently attributed to instrument noise. Furthermore, the measurement error cannot be expected to become zero (as mentioned in theoretical discussion in Sect. 2) even when a better correction algorithm is used. There are several possible reasons for this issue. First, the optimized algorithm can only minimize measurement error caused by nonlinear absorption, but it cannot correct the instrumentation error caused by a detector, an electronics device noise, or any incomplete adjustments for system drift. Second, $\mathrm{CO}$ and $\mathrm{CO}_{2}$ not only interfere with each other but are also interfered with by other gases. The impurities in the calibration gas and $\mathrm{N}_{2}$, such as $\mathrm{NO}, \mathrm{NO}_{2}, \mathrm{H}_{2} \mathrm{O}$, and others, also result in errors. The $\mathrm{CO}_{2}$ channel is especially interfered with by water vapor. The high concentrations of water vapor in the atmosphere that leak into the sample cell during the cylinder conversion period also affect the experimental result. However, this effect can be corrected easily by excluding the experiment data collected in

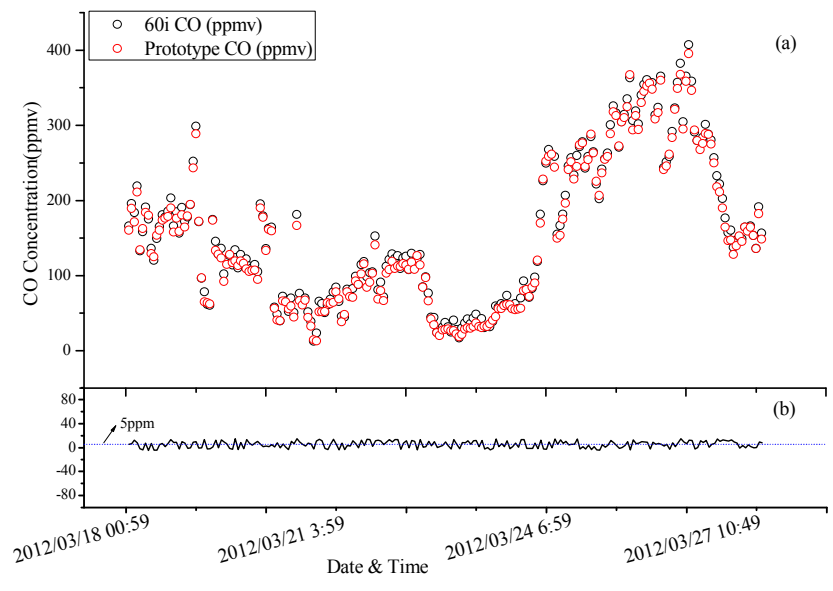

Fig. 10. (a) Time series of the $\mathrm{CO}$ volume-mixing ratio measured by the NDIR Model 60i and the NDIR analyzer prototype. The difference between the $\mathrm{CO}$ concentrations measured by Model 60i and the prototype are shown in (b). Outliers are removed and the data are presented as hourly averages.

the cylinder conversion period and averaging the data sevenfold. Although error sources are unavoidable, the experimental results can still fully prove the superiority of the optimized algorithm, which can correct cross interference well both for linear and nonlinear absorption.

\subsection{Comparison of the two algorithms}

A conceptual comparison of the classical and optimized cross interference correction algorithm is presented in Table 2. The processing speed is also compared in addition to the characteristics deduced from the above mathematical descriptions and discussions. The classical algorithm offers a faster processing speed than the optimized algorithm because of the relatively simpler equations to be solved.

The choice of cross interference correction algorithm has to be matched ideally to the specific requirements by balancing the assets and drawbacks of the different approaches in the selection process. Three cases can be identified based on different applications.

1. Case 1: all gases (including the target gases and the interference gases) exhibit linear absorption. Both the classical and the optimized cross interference correction algorithms work well. However, the classical algorithm is used in most cases because a relatively faster processing speed can be obtained.

2. Case 2: all gases exhibit nonlinear absorption. The optimized algorithm is generally used if all gases exhibit nonlinear absorption.

3. Case 3: a case between Case 1 and Case 2. In this case, the classical algorithm fails while the optimized one is still applied. However, the interference equations should 


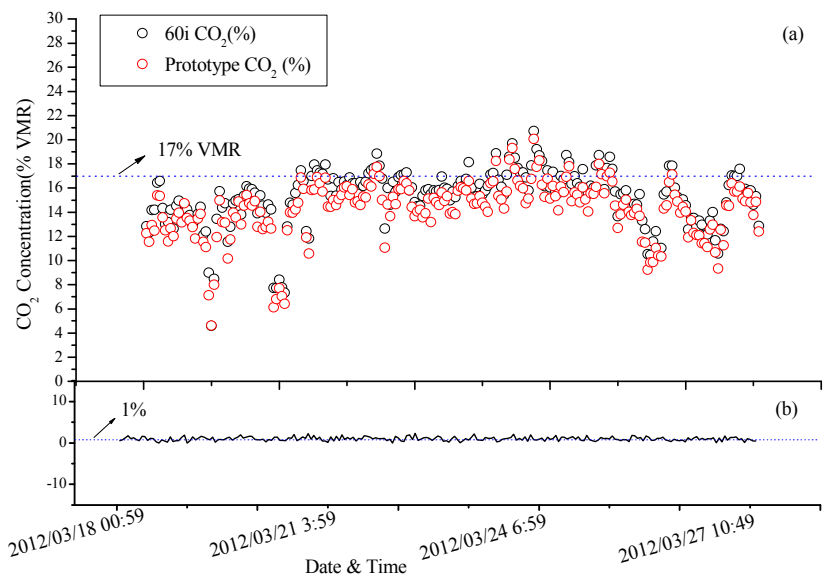

Fig. 11. (a) Time series of the $\mathrm{CO}_{2}$ volume-mixing ratio measured by the NDIR Model 60i and the NDIR analyzer prototype. The difference between the $\mathrm{CO}_{2}$ concentrations measured by Model $60 \mathrm{i}$ and prototype are shown in (b). Outliers are removed and the data are presented as hourly averages.

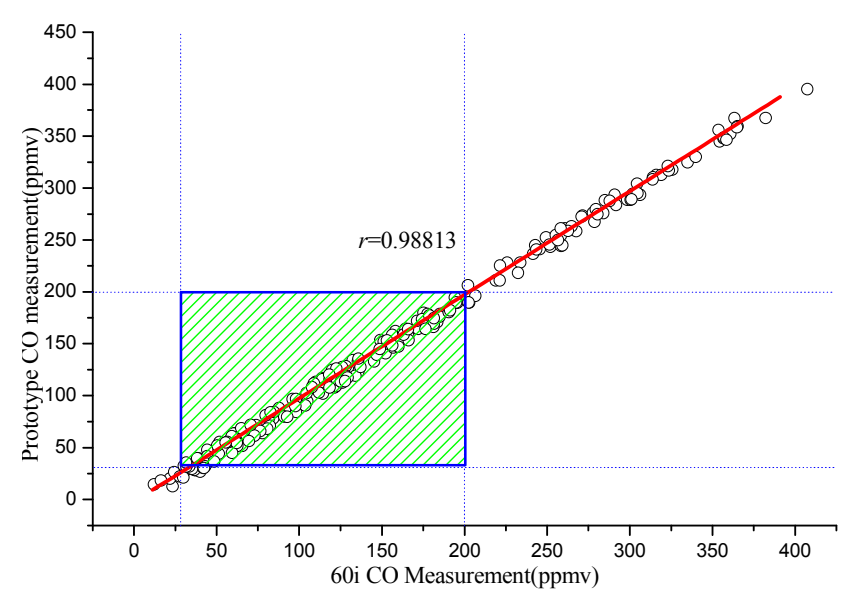

Fig. 12. CO measurement correlation between Model 60i and the NDIR analyzer prototype after the outliers are removed. The measurement correlation coefficient $r$ is visible in the figure. The blue box shows the concentration range where $\mathrm{CO}$ appeared with the highest frequency.

be set up in a compromising way. More precisely, the interference of the linear absorption gas to the nonlinear absorption gas is corrected by a constant factor. However, the interference of the nonlinear absorption gas to the linear absorption gas is corrected by utilizing a fitted interference function. This method not only compensates the nonlinear absorption problem well, but also improves the processing speed. The interference equations can actually be set up as this form based on the fact that the optimized algorithm is a generalization of the classical algorithm. The classical algorithm can be derived from the optimized one if (1) all gases (including the target gases and the interference gases) exhibit
Table 2. Comparison of the classical and optimized cross interference correction algorithm.

\begin{tabular}{|c|c|c|c|c|}
\hline Algorithm & $\begin{array}{l}\text { Linear } \\
\text { absorption }\end{array}$ & $\begin{array}{l}\text { Nonlinear } \\
\text { absorption }\end{array}$ & $\begin{array}{l}\text { Measurement } \\
\text { range }\end{array}$ & $\begin{array}{l}\text { Processing } \\
\text { speed }\end{array}$ \\
\hline Classical & Yes & No & Narrow & Fast \\
\hline Optimized & Yes & Yes & Wide & Slow \\
\hline
\end{tabular}

linear absorption, and if (2) a linear model " $y=k x$ " is used to model the gas-to-gas interference during leastsquares fitting.

The selection of the cross interference correction algorithm for simultaneous two-gas (e.g., gases $i$ and $j$ mentioned in the former sections) analysis is presented in Table 3 . The expansion to more than two gases is straightforward.

\section{$5 \quad$ Field applications}

Instruments with high accuracy can be used to validate the optimized algorithm. In the present study, a commercial NDIR multi-gas analyzer Model 60i manufactured by Thermo Fisher Scientific, Inc. was used to validate the CO and $\mathrm{CO}_{2}$ results measured by the NDIR analyzer prototype, in which an optimized cross interference correction algorithm was embedded. The field experiment was operated from 18 to 27 March 2012 in the Shangfeng cement plant $\left(30.48^{\circ} \mathrm{N}, 117.48^{\circ} \mathrm{E}\right)$ located south of Tongling city (south of Hefei, Anhui province) in central China. The prototype $\mathrm{CO}$ and $\mathrm{CO}_{2}$ measurements were synchronously compared with the Model 60i measurements. Both analyzers, placed in a mini house built at above $15 \mathrm{~m}$ height, measured the stack emission from the cement plant. The field setup and gas pipe connection diagram are shown in Fig. 9. Both analyzers were zero and span calibrated with the same calibration gases before the experiment. Both analyzers had pressure and temperature drift compensation for the measurements to improve accuracy. The performance specifications comparison of the two analyzers for $\mathrm{CO}_{2}$ and $\mathrm{CO}$ is listed in Table 4. Model 60i used the classical algorithm to correct the cross interference among different gases. Model 60i can correct cross interference well because all gas concentrations (during the whole field experiment) were within the analyzer's linear dynamic range. Thus, the five target gases (i.e., $\mathrm{CO}_{2}, \mathrm{CO}, \mathrm{NO}, \mathrm{NO}_{2}$, and $\left.\mathrm{SO}_{2}\right)$ were retrieved with a high accuracy $(< \pm 2 \%)$ (Instruction Manual-Model 60i).

The gas emission samples collected from the stack were pumped into a pretreatment system with a heat-tracing pipe. Then, the samples were imported into the two analyzers with a four-port distribution chamber after being pretreated. The sample system blows back once an hour to prevent the dust filter from being jammed. The samples pumped into two analyzers during this period were a mixture of emission residuals 
Table 3. Selection of the cross interference correction algorithm for simultaneous two-gas analysis; gas $i$ and $j$ mentioned in former sections are taken as an example.

\begin{tabular}{llll}
\hline Case & $\begin{array}{l}\text { Nonlinear absorption } \\
\text { behaviors }\end{array}$ & $\begin{array}{l}\text { Selection of the } \\
\text { cross interference } \\
\text { correction algorithm }\end{array}$ & Implementation of the interference equations \\
\hline $1 \quad \begin{array}{l}\text { Neither gas } i \text { nor } j \text { has } \\
\text { nonlinear absorption. }\end{array}$ & Classical & $\begin{array}{l}\text { Both the interference of gas } i \text { to } j \text { and gas } j \\
\text { to } i \text { are corrected using a constant factor. }\end{array}$ \\
\hline $2 \quad \begin{array}{l}\text { Gas } i \text { has nonlinear } \\
\text { absorption, but gas } j \\
\text { does not. }\end{array}$ & Optimized & $\begin{array}{l}\text { The interference of gas } j \text { to } i \text { is corrected us- } \\
\text { ing a constant factor. However, the interfer- } \\
\text { ence of gas } i \text { to } j \text { is corrected using a fitted } \\
\text { interference function. }\end{array}$ \\
\hline 3 & $\begin{array}{l}\text { Gas } j \text { has nonlinear } \\
\text { absorption, but gas } i \\
\text { does not. }\end{array}$ & Optimized & $\begin{array}{l}\text { The interference of gas } i \text { to } j \text { is corrected us- } \\
\text { ing a constant factor. However, the interfer- } \\
\text { ence of gas } j \text { to } i \text { is corrected using a fitted } \\
\text { interference function. }\end{array}$ \\
\hline 4 & $\begin{array}{l}\text { Both gas } i \text { and } j \text { have } \\
\text { nonlinear absorption. }\end{array}$ & Optimized & $\begin{array}{l}\text { Both the interference of gas } i \text { to } j \text { and gas } j \\
\text { to } i \text { are corrected using a fitted interference } \\
\text { function. }\end{array}$ \\
\hline
\end{tabular}

Table 4. Performance specifications comparison of the prototype and Model $60 \mathrm{i}$ for $\mathrm{CO}_{2}$ and $\mathrm{CO}$, where only parts of the performance specifications used for discussion in the text are compared.

\begin{tabular}{lllll}
\hline Instrument & \multicolumn{2}{c}{ NDIR Model 60i } & \multicolumn{2}{c}{ NDIR prototype } \\
\hline Compound & $\mathrm{CO}$ & $\mathrm{CO}_{2}$ & $\mathrm{CO}$ & $\mathrm{CO}_{2}$ \\
Lower detection & $1 \mathrm{ppmv}$ & $500 \mathrm{ppmv}$ & $0.4 \mathrm{ppmv}$ & $300 \mathrm{ppmv}$ \\
Dynamic range with & & & & \\
linearity error $\leq \pm 2 \%$ & $0 \sim 2500 \mathrm{ppmv}$ & $0 \sim 25 \%$ & $0 \sim 850 \mathrm{ppmv}$ & $0 \sim 17 \%$ \\
Measurement error & $\pm 2 \%$ & $\pm 2 \%$ & $\pm 1 \%$ & $\pm 1.5 \%$ \\
\hline
\end{tabular}

in the chamber and ambient air. Both the prototype and Model 60i were set to save minute averaged measurements, which facilitated the outliers' (measurements acquired during blowback periods) removal in data post-processing.

There were still residual amounts of $\mathrm{SO}_{2}$ and $\mathrm{NO}_{\mathrm{x}}$ in the gas emission samples despite the performance of the desulfurization and denitrification before the smoke was emitted to the atmosphere (Chan and Yao, 2008; Terje, 1996; Zu, 2002; Ackerman and Sundquist, 2008; Bovensmann et al., 2010; EPER, 2004; European Commission, 2007; Evans et al., 2009; Dong et al., 2011). Furthermore, the water vapor should not be neglected despite the pretreatment of the emission samples before being pumped into the two analyzers (Sun et al., 2011). All these gases may have noticeable absorption interference to the $\mathrm{CO}$ and $\mathrm{CO}_{2}$ measurements. If not corrected, the measurement error would increase. However, all gases ( $\mathrm{CO}$ and interfering gases $\mathrm{H}_{2} \mathrm{O}, \mathrm{NO}, \mathrm{NO}_{2}$, and $\mathrm{SO}_{2}$ ) lay within the linear dynamic range of the prototype apart from $\mathrm{CO}_{2}$ (beyond $17 \%$ ), which was similar to Case 3 listed in Sect. 4.3. The classical algorithm in this case was not feasible and the optimized algorithm had to be applied.
More precisely, the correction for the interference of $\mathrm{CO}_{2}$ to other gases (mainly $\mathrm{CO}$ and $\mathrm{NO}$ ) utilized the fitted interference functions. However, the correction for the interference of other gases (mainly $\mathrm{CO}, \mathrm{H}_{2} \mathrm{O}, \mathrm{SO}_{2}$, and $\mathrm{NO}$ ) to $\mathrm{CO}_{2}$ utilized the interference constants. This method facilitated the interference equations solution without a decline in the correction effects.

In the present study, six equations were set up based on signal detected from the six filter channels by using all the interference constants or interference functions. However, only the $\mathrm{CO}$ and $\mathrm{CO}_{2}$ concentrations were retrieved and compared with Model 60i measurements.

A large amount of individual measurements were obtained from 00:59 UTC+8 of 18 March to 10:49 of 27 March 2012. Figures 10a and 11a were hour-averaged series for the $\mathrm{CO}$ and $\mathrm{CO}_{2}$ mixing ratio measured by both analyzers during the whole field experiment. In both figures, the measurements acquired during blowback periods were removed. Figures $10 \mathrm{~b}$ and $11 \mathrm{~b}$ present the difference between the $\mathrm{CO}$ and $\mathrm{CO}_{2}$ concentrations measured by Model $60 \mathrm{i}$ and the prototype, respectively. Both figures show that the Model $60 \mathrm{i}$ 


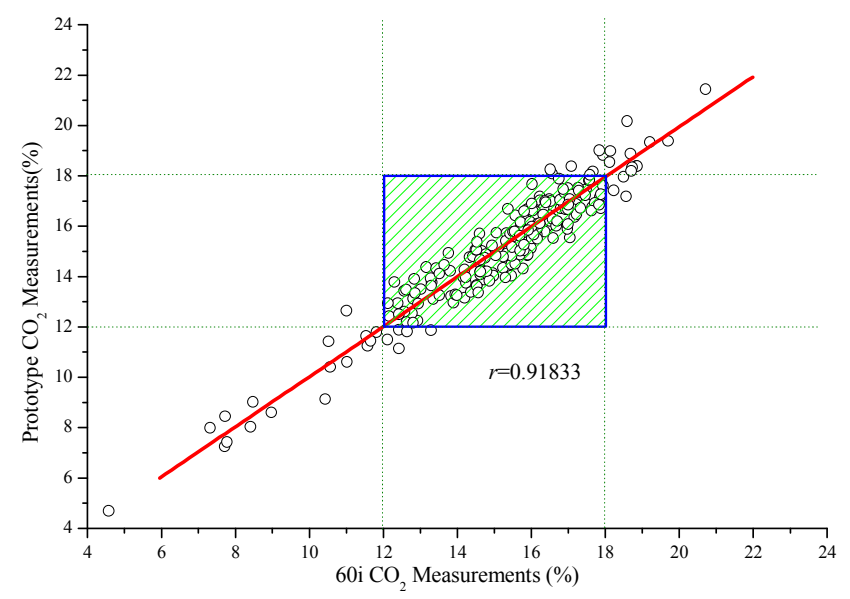

Fig. 13. $\mathrm{CO}_{2}$ measurement correlation between Model $60 \mathrm{i}$ and the NDIR analyzer prototype after the outliers are removed. The measurement correlation coefficient $r$ is visible in the figure. The blue box shows the concentration range where $\mathrm{CO}_{2}$ appeared with the highest frequency.

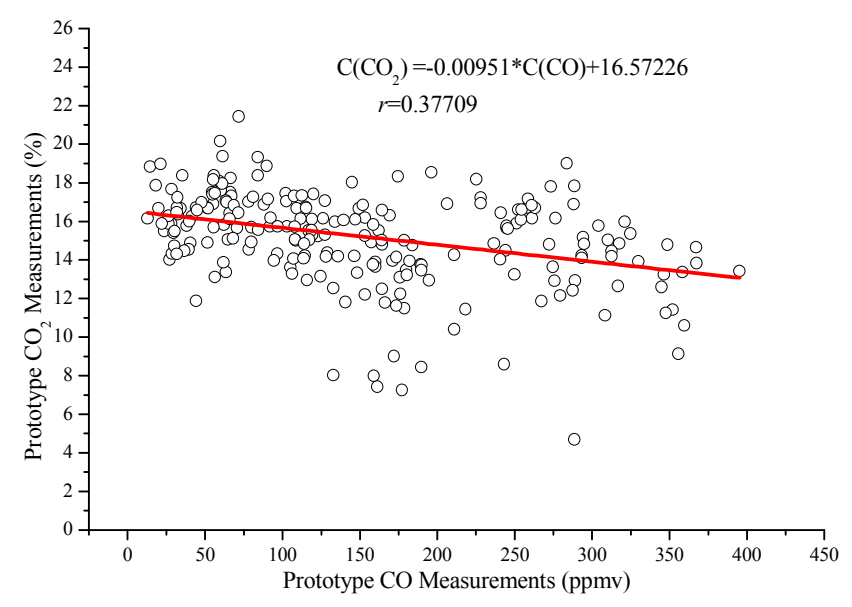

Fig. 14. Correlation between $\mathrm{CO}_{2}$ and $\mathrm{CO}$ measured by the NDIR analyzer prototype. Both the measurement correlation coefficient $r$ and the fitted correlation equation are visible in the figure.

measurements were a little higher than those of the prototype ( $\mathrm{CO}$ and $\mathrm{CO}_{2}$ were $\sim 5$ ppmv and $\sim 1 \%$ higher, respectively). These differences were mainly attributed to calibration error, and had little to do with the cross interference correction results. These differences can be minimized through repeated calibration. Although there were some deviations, the two analyzers exhibited approximately the same concentration trend. The $\mathrm{CO}$ concentration was less than $400 \mathrm{ppmv}$ and was mainly concentrated in $\sim 30 \mathrm{ppmv}$ to $200 \mathrm{ppmv}$, whereas the $\mathrm{CO}_{2}$ concentration was mainly between $12 \%$ to $18 \%$.

Figures 12 and 13, presenting the $\mathrm{CO}$ and $\mathrm{CO}_{2}$ measurement correlation coefficient $r$, respectively, show the measurement correlation between the two analyzers after the outliers (i.e., measurements acquired during blowback

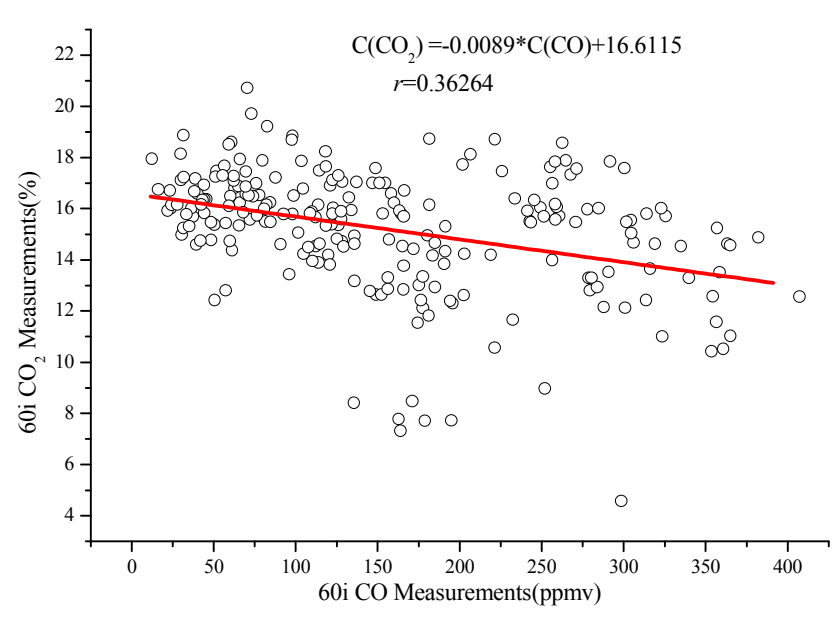

Fig. 15. Correlation between $\mathrm{CO}_{2}$ and $\mathrm{CO}$ measured by NDIR analyzer Model 60i. Both the measurement correlation coefficient $r$ and the fitted correlation equation are visible in the figure.

periods) were removed. Both figures show that a regression analysis for the $\mathrm{CO}$ and $\mathrm{CO}_{2}$ measurements of the two analyzers presented a high correlation coefficient, wherein the measurement correlation coefficient for CO was $r=0.98813$ and for $\mathrm{CO}_{2}$ was $r=0.91833$. The measurement correlation of the two analyzers for $\mathrm{CO}$ was better than that for $\mathrm{CO}_{2}$ because of the higher absorption intensity of $\mathrm{CO}$ compared with $\mathrm{CO}_{2}\left(\sim 10^{-18}\right.$ molec cm ${ }^{-2}$ vs. $\sim 10^{-21}$ molec cm $\left.\mathrm{cm}^{-2}\right)$. Therefore, the $\mathrm{CO}$ filter channel was more sensitive to optical signal attenuation than that of $\mathrm{CO}_{2}$. In other words, the system noise with the same level had less influence on $\mathrm{CO}$ than on $\mathrm{CO}_{2}$. Besides, $\mathrm{CO}_{2}$ was also more heavily interfered with by $\mathrm{H}_{2} \mathrm{O}, \mathrm{NO}, \mathrm{NO}_{2}$, and $\mathrm{SO}_{2}$ than $\mathrm{CO}$ was according to the spectral parameters in the HITRAN database (Rothman et al., 2005, 2009). The interference of $\mathrm{NO}, \mathrm{NO}_{2}$, and $\mathrm{SO}_{2}$ with $\mathrm{CO}$ was negligible compared with the interference of $\mathrm{H}_{2} \mathrm{O}$. However, $\mathrm{H}_{2} \mathrm{O}, \mathrm{NO}, \mathrm{NO}_{2}$, and $\mathrm{SO}_{2}$ all had pronounced interference with $\mathrm{CO}_{2}$. It indicates that the interference with $\mathrm{CO}$ was more easily corrected than that with $\mathrm{CO}_{2}$. The dense "point" regions within the blue boxes (in both Figs. 12 and 13) represent the concentration ranges where the gases appeared with the highest frequency. The $\mathrm{CO}$ concentrations were mainly concentrated in between $30 \mathrm{ppmv}$ to $200 \mathrm{ppmv}$, and the $\mathrm{CO}_{2}$ concentrations were mainly concentrated in between $12 \%$ and $18 \%$, which agrees with Figs. 10 and 11.

Finally, the concentration correlation analysis between $\mathrm{CO}_{2}$ and $\mathrm{CO}$ measured by both analyzers was performed to study the characteristics of pollutant gas emissions. Figures 14 and 15 show the correlation between the $\mathrm{CO}_{2}$ and $\mathrm{CO}$ measured respectively by the prototype and Model $60 \mathrm{i}$. The analysis in both figures revealed that there was a certain negative correlation between the concentrations, i.e., the $\mathrm{CO}_{2}$ concentration reduced as $\mathrm{CO}$ concentration increased. This dependence exhibited in the prototype and Model 60i are expressed as Eqs. (16) and (17) with the correlation 
coefficient of $r=0.37709$ and 0.36624 for $\mathrm{CO}_{2}$ to $\mathrm{CO}$, respectively.

$$
\begin{aligned}
C\left(\mathrm{CO}_{2}\right) & =(-0.00951 \pm 0.0015) \\
& \times C(\mathrm{CO})+(16.57226 \pm 0.26934) \\
C\left(\mathrm{CO}_{2}\right) & =(-0.0089 \pm 0.00151) \\
& \times C(\mathrm{CO})+(16.6115 \pm 0.27455)
\end{aligned}
$$

The units for $\mathrm{CO}_{2}$ and $\mathrm{CO}$ in both equations were $\%$ and ppmv, respectively. A detailed discussion of the characteristics of the pollutant gas emissions of this cement plant or the relationship between the gas emissions and the specific production process exceeds the scope of this article, and will be published elsewhere separately.

\section{Conclusions}

Accuracy and sensitivity depend largely on the results of cross interference correction if the gases are measured simultaneously by using the NDIR technique. An NDIR analyzer with a constant path length exhibits nonlinear absorption if the gas concentrations go beyond a restricted range, resulting in the variation of the interference coefficients with the interfering gas concentration. The classical algorithm for cross interference fails in this case. In the present paper, an optimized cross interference correction algorithm modified from the classical one is presented. An interference function rather than a constant factor is used to qualify the gas-to-gas interference. When the analyzer exhibits nonlinear absorption, the interference coefficient determined by interference function varies correspondingly. So the optimized algorithm can correct cross interference well both for linear and nonlinear absorption. Thus, the dynamic measurement range of an NDIR analyzer can be expanded if an optimized algorithm is used. In the last part, a commercial NDIR analyzer is used to validate the $\mathrm{CO}$ and $\mathrm{CO}_{2}$ measurements derived from an NDIR prototype, in which an optimized cross interference correction algorithm is embedded. The comparison is performed within the linear range of the commercial NDIR analyzer, and the two analyzers' measurements exhibit approximately the same concentration trend, and a negative correlation between $\mathrm{CO}_{2}$ and $\mathrm{CO}$ is derived from the measurements of both analyzers.

Acknowledgements. This work is jointly supported by the Special Scientific Research Fund of Meteorological Public Welfare Profession of China (Grant No. GYHY201106045-1 and No. 201109007), Anhui Province Natural Science Foundation of China (Grant No. 1308085QF124), and the National Natural Science Foundation of China (Grant No. 41275037 and No. 41105011). We thank X. Zhou, manager of the Shangfeng cement plant, for our access to the field site, and C. Liu for his valuable comments on the manuscript.

Edited by: J. Hjorth

\section{References}

Ackerman, K. V. and Sundquist, E. T.: Comparison of Two U.S. Power-Plant Carbon Dioxide Emissions Data Sets, Environ. Sci. Technol., 42, 5688-5693, doi:10.1021/es800221q, 2008.

Andre, G., Gerard, F., and Pierre, C.: Gas concentration measurement by spectral correlation: rejection of interferent species, Appl. Opt., 14, 2127-2132, 1985.

Bingham, D. and Burton, C. H.: Analysis of multi-component gas mixtures by correlation of infrared spectra, Appl. Spectrosc., 5, 705-709, 1984.

Bjorck, A.: Numerical Methods for Least Squares Problems, SIAM, Society for Industrial and Apllied Mathematics, SIAM, University City Science Center, Philadelphia, PA, available at: http:// www.ec-securehost.com/SIAM/ot51.html (last access: 2 February 2012), 1996.

Bovensmann, H., Buchwitz, M., Burrows, J. P., Reuter, M., Krings,T., Gerilowski, K., Schneising, O., Heymann, J., Tretner, A., and Erzinger, J.: A remote sensing technique for global monitoring of power plant $\mathrm{CO}_{2}$ emissions from space and related applications, Atmos. Meas. Tech., 3, 781-811, doi:10.5194/amt-3781-2010, 2010.

Chan, C. K. and Yao, X.: Air pollution in mega cities in china, Atmos. Environ., 42, 1-42, 2008.

Derek, Y.: Least squares fitting of a straight line with correlated errors, Earth Planet. Sci. Lett., 5, 320-324, 1968.

Dirk, A., Gaston, E. M., Shrikrishna, H. N., and Robert F. M.: Gas Analyzer System, US Pat US/2009/0213380 A1, US, 27 August, 2009.

Dong, F. Z., Liu, W. Q., Chu, Y. N., Li, J. Q., Zhang, Z. R., Wang, Y., Pang, T., Wu, B., Tu, G. J., Xia, H., Yang, Y., Shen, C. Y., Wang, Y. J., Ni, Z. B., and Liu, J. G.: Real-Time In Situ Measurements of Industrial Hazardous Gas Concentrations and Their Emission Gross, Environmental Monitoring, edited by: Ekundayo, E., InTech, available at: www.intechopen.com/books/environmentalmonitoring, 2011.

EPER: European Pollutant Emission Register 2004, available at: http://eper.ec.europa.eu/ (last access: 1 February 2011), 2004.

European Commission: 2007/589/EC, establishing guidelines for the monitoring and reporting of greenhouse gas emissions pursuant to Directive 2003/87/EC of the European Parliament and of the Council, Official Journal of the European Union, 2210, 2007.

Evans, S., Deery, S., and Bionda, J.: How Reliable are GHG Combustion Calculations and Emission Factors, Presented at the CEM 2009 Conference, 23-25 September, Milan, Itlay, 2210, 2240, 2009.

Gary, K.: An open path $\mathrm{H}_{2} \mathrm{O} / \mathrm{CO}_{2}$ gas analyzer for eddy correlation systems: theory and design, Spectrochimica Acta Part A, 58, 2373-2388, 2002.

Harold, S. L., Satoru, S., Louis, J. D., and Alberto, M. G.: NoneDispersive Infrared Gas Analyzer with Interfering Correction, US Pat 5886348, 23 March, 1999.

Herget, W. F., Jahnke, J. A., Burch, D. E., and Gryvnak, D. A.: Infrared Gas Filter Correlation Instrument for in situ Measurement of Gaseous Pollutant Concentrations, Appl. Opt., 15, 1222-1225, 1976.

Heusinkveld, B. G., Adrie, F. G. J., and Albert, A. M. H.: Effect of open path gas analyzer wetness on eddy covariance flux measurement: A proposed solution, Agr. Forest Meteorol., 148, 1563- 
1573, 2008.

Hikmat, H. A., Islam, M. M., and Davud, Z. A.: Synthesis of corrected multi-wavelength spectrometers for atmospheric trace gases, Chin. Opt. Lett., 5, 361-363, 2009.

Instruction Manual-Model 60i, available at: http://www.ayt.cl/pdf/ thermo.pdf, last access: 18 July, 2011.

Instruction Manual-L-7200/7500: available at: http://www.licor. com/env/Products/GasAnalyzers/7200/7200.jsp, last access: 12 July, 2012.

Jong, S. P., Hee, C. C., and Seung, H. Y.: NDIR CO2 gas sensor with improved temperature compensation, Proc. Eng., 5, 303306, 2010.

Komhyr, W. D., Harris, T. B., Waterman, L. S., Chin, J. F. S., and Thoning, K. W.: Atmospheric carbon dioxide at Mauna Loa observatory: 1. NOAA global monitoring for climatic change measurements with a non-dispersive infrared analyzer, J. Geophys. Res.-Atmos., 94, 7-29, 1989.

Komhyr, W. D., Waterman, L. S., and Taylor, W. R.: Semiautomatic non-dispersive infrared analyzer apparatus for $\mathrm{CO}_{2}$ air sample analyses, J. Geophys. Res., 88, 1315-1322, doi:10.1029/JC088iC02p01315, 1983.

Lopez, F. and de Frutos, J.: Multi-spectral interference filters and their application to the design of compact non-dispersive infrared gas analyzers for pollution control, Sensors and Actuators A: Physical, 37, 502-506, 1993.

Liu, C., Beirle, S., Butler, T., Liu, J., Hoor, P., Jöckel, P., Penning de Vries, M., Pozzer, A., Frankenberg, C., Lawrence, M. G., Lelieveld, J., Platt, U., and Wagner, T.: Application of SCIAMACHY and MOPITT CO total column measurements to evaluate model results over biomass burning regions and Eastern China, Atmos. Chem. Phys., 11, 6083-6114, doi:10.5194/acp11-6083-2011, 2011.

Marcel, M., Andreas, D., and Zuberbuehler, A.: Nonlinear leastsquares fitting of multivariate absorption data, Anal. Chem., 62, 2220-2224, 1990.

Mark, A. M., Chris, W. B., and Donald, S. L.: Nonlinear Multi-component Analysis by Infrared Spectrophotometry, Anal. Chem., 11, 1694-1703, 1983.

Martin, K. and Michael, H.: Efficient line-by-line calculation of absorption coefficients, J. Quant. Spectrosc. Ra., 63, 97-114, 1999.

Mauri, A. R., Llobat, M., and Adria, D.: Detection and correction of interference in spectroscopy techniques, Analy. Chim. Acta, 426, 135-146, 2001.

Rao, C. R., Toutenburg, H., Fieger, A., Heumann, C., Nittner, T., and Scheid, S.: Linear Models: Least Squares and Alternatives, Springer Series in Statistics, Springer-Verlag New York, Inc., New York, 1999.
Rothman, L., Jaquemart, D., Barbe, A., Benner, D. C., Birk, M., Brown, L., Carleer, M., Jr., C., Chance, K., Coudert, L., Dana, V., Devi, V., Flaud, J.-M., Gamache, R., Goldman, A., Hartmann, J. -M., Jucks, K., Makim, A., Mandin, J. -Y., Massie, S., Orphalh, J., Perrin, A., Rinsland, C., Smith, M., Tennyson, J., Tolchenov, R., Toth, R., Auwera, J. V., Varanasi, P. and Wagner, G.: The HITRAN 2004 molecular spectroscopic database, J. Quant. Spectrosc. Ra., 96, 139-204, doi:10.1016/j.jqsrt.2004.10.008, 2005.

Rothman, L., Gordon, I., Barbe, A., Benner, D., Bernath, P., Birk, M., boudon, V., Brown, L., Campargue, A., Champion, J.-P., Chance, K., Coudert, L., Dana, V., Devi, V., Fally, S., Flaud, J.M., Gamache, R., Goldman, A., Jacquemart, D., Kleiner, I., Lacome, N., Lafferty,W., Mandin, J.-Y., Massie, S., Mikhailenko, S., Miller, C., Moazzen-Ahmadi, N., Naumenko,O., Nikitin, A., Orphal, J., Perevalov, V., Perrin, A., Predoi-Cross, A., Rinsland, C., Rotger, M., Simeckova, M., Smith, M., Sung, K., Tashkun, S., Tennyson, J., Toth, R., Vandaele, A., and Auwera, J. V.: The HITRAN 2008 molecular spectroscopic database, J. Quant. Spectrosc. Ra., 110, 533-572, doi:10.1016/j.jqsrt.2009.02.013, 2009.

Sayed, A. M. M. and Mohamed, H. A.: Gas analyzer for continuous monitoring of carbon dioxide in gas streams, Sensors and Actuators B: Chemical, 145, 398-404, 2010.

Sparks, L. : Efficient line-by-line calculation of absorption coefficients, J. Quant. Spectrosc. Ra., 57, 31-50, 1997.

Sun, Y. W., Liu, W. Q., Wang, S. M., Huang S. H., and Yu X. M.: Water Vapor Interference Correction in a Non-Dispersive Infrared Multi-Gas Analyzer, Chin. Phys. Lett., 7, 73302-73305, 2011.

Tan, Q. L., Zhang, W. D., Xue, C. Y., Xiong, J. J., Ma, Y. C., and Wen F.: Design of mini-multi-gas monitoring system based on IR absorption, Opt. Laser Technol., 40, 703-710, 2008.

Terje, B.: Impact of increased anthropogenic emission in Asia on tropospheric ozone and climate, Tellus, 3, 251-254, 1996.

Tyson, L., Ling, Y. C., and Charles K. M.: Simultaneous Multicomponent Quantitative Analysis by Infrared Absorption Spectroscopy, Appl. Spectrosc., 5, 38-56, 1984.

Yan, W. D., Tian, Z., Pan, L. L., and Ding, M. T.: Spectral feature matching based on partial least squares, Chin. Opt. Lett., 3, $201-$ 205, 2009.

$\mathrm{Zu}$, S. F.: Present status and developing countermeasure of tail exhaust gas measurement of China motor vehicle, Auto. Ind. Res., 4, 25-28, 2002. 